\title{
A técnica de dopagem no tratamento da zona de interface: ligações entre concreto novo e velho
}

\author{
The doping technique in the interface zone treatment: \\ fresh and old concrete connections
}

\begin{abstract}
Ana Paula Moreno Trigo
Rodrigo Vieira da Conceição

Jefferson Benedicto Libardi Liborio

Resumo

Ana Paula Moreno Trigo Escola de Engenharia de São

Carlos

Universidade de São Paulo Av. Trabalhador Sãocarlense, 400, Centro São Carlos - SP - Brasil CEP $13566-590$

Tel.: (16) 3373-8208

E-mail: apmtrigo@sc.usp.br

Rodrigo Vieira da Conceição

Laboratório de Materiais Avançados à Base de Cimento,

Escola de Engenharia de São

Carlos

Universidade de São Paulo

Te.: (16) 3373-8208

E-mail: rvieira@sc.usp.br

Prof. Dr. Jefferson B.

Libardi Liborio

Departamento de Arquitetura e

Urbanismo

Universidade de São Paulo

Av. Trabalhador Sãocarlense, 400, Centro

São Carlos - SP - Brasil CEP 13566-590

Tel.: (16) 3373-8209

E-mail: liborioj@sc.usp.br

Recebido em 13/05/09

Aceito em 22/01/10

$\mathbf{P}$

ara que as estruturas de concreto alcancem uma vida útil adequada é necessário avaliar a durabilidade e considerar a manutenção das mesmas. Isso tem estimulado o desenvolvimento de tecnologias destinadas a solucionar a problemática de peças deterioradas ou danificadas. Este trabalho analisa o comportamento da zona de interface entre concreto novo e velho após a escarificação do concreto velho (tratamento físico) e o emprego da técnica de dopagem (tratamento químico). A técnica de dopagem consiste na impregnação de pó por via seca ou pasta de alto desempenho, seguida do lançamento de concreto novo, ou no lançamento direto de um concreto novo com características de alto desempenho. $\mathrm{O}$ desempenho dessa ligação foi avaliado por meio de ensaios de tração na flexão, até a ruptura, em corpos de prova prismáticos de concreto simples $\left(\mathrm{f}_{\mathrm{ck}}=20 \mathrm{MPa}\right)$ e em seguida remoldados. A partir dos resultados, verificou-se que a ruptura dos corpos de prova recuperados ocorreu fora da região de interface e que as resistências à flexão desse concreto foram mantidas tais quais as originais, demonstrando a eficácia do procedimento na ligação entre concreto novo e velho.

Palavras-chave: Dopagem. Reparo. Ligação. Alto desempenho. Durabilidade.

\section{Abstract}

In order for concrete structures to have an adequate lifetime it is necessary to assess their durability and also to consider their maintenance. This has encouraged the development of specific technologies to solve problems concerning deteriorated and damaged parts. This study analyses the behavior of the interface zone between fresh and old concrete after scraping the old concrete (physical treatment) and also using the doping technique (chemical treatment).

The doping technique consists in dry powder or high performance paste impregnation followed by fresh concrete pouring, or direct pouring of fresh high performance concrete. The performance of that connection was evaluated through flexural tensile tests until failure. The tests were carried out on conventional concrete prismatic specimens $\left(f_{c k}=20 \mathrm{MPa}\right)$. At the end of the tests the specimens were remolded. The results indicated that the failure in the remolded specimens occurred outside the interface zone and the flexure resistance values were the same when compared to the original values, showing the efficacy of the procedure for connecting fresh and old concrete.

Keywords: Doping. Repair. Connection. Connection. High-performance. Durability.
\end{abstract}




\section{Introdução}

Projetar uma estrutura de concreto armado, atualmente, não diz respeito somente aos conceitos estruturais (dimensões, bitolas, resistências, etc.). É necessário que o projetista conheça as possíveis interferências do meio ambiente ou da microrregião nos quais estará exposta a edificação ou suas partes e, também, as características e a sinergia entre os materiais constituintes do concreto, evitando possível patologia. Isso também pode surgir devido à execução incorreta da estrutura ou até mesmo pelo mau uso da edificação.

Diante dessa problemática, faz-se necessário o amplo conhecimento das características de todos os materiais e processos envolvidos na moldagem dos elementos que compõem a estrutura de concreto, além da consideração do conceito de durabilidade.

Para Laranjeiras (2002), apesar de o concreto ser considerado um material de grande durabilidade, desde que receba manutenção sistemática e programada, no decorrer do século $\mathrm{XX}$, as estruturas de concreto tornaram-se, progressivamente, menos duráveis.

Silva (2002) avaliou composições de traços objetivando verificar a durabilidade de elementos estruturais ante a ação da carbonatação. Entre os estudos, foram avaliados corpos de prova de concretos com agregados graúdos de $\mathrm{D}_{\text {máx }} \leq 9,5$ $\mathrm{mm}$ executados com cimentos Portland de alta resistência inicial, com e sem adição de sílica ativa. Mesmo sem sílica ativa, a profundidade à carbonatação, em ensaios acelerados, não foi muito intensa $(8 \mathrm{~mm})$. Esse bom resultado se deveu a uma boa compacidade do concreto, a uma baixa relação água/cimento e a um bom planejamento da concretagem.

Além da carbonatação, outro mecanismo de deterioração importante é a ação de cloretos no concreto. O programa experimental desenvolvido por Silva (2006) consistiu em analisar as propriedades de concretos com agregados de $\mathrm{D}_{\text {máx }}$ $\leq 9,5 \mathrm{~mm}$ e com sílica de ativa, verificando sua capacidade de proteção ao aço nas estruturas de concreto armado. Foi observado que os íons cloretos não atingiram a armadura em nenhum dos concretos estudados e, portanto, não houve risco para o início da corrosão.

No entanto, a falta de atenção a aspectos relativos à durabilidade, nas etapas de projeto e execução, associada à agressividade do ambiente de exposição acarretam na deterioração prematura das estruturas de concreto armado. Aliado a isso, os acidentes de origem natural ou humana, a falta de manutenção e a detecção de falhas nas fases de projeto e de execução justificam o emprego crescente das técnicas de reparo e reforço de estruturas de concreto, sendo, consequentemente, cada vez mais necessário o aperfeiçoamento delas.

Um dos problemas enfrentados diariamente em canteiros de obras está relacionado à ligação entre concretos executados em diferentes idades e com diferentes composições e resistências. Esse tipo de ligação pode ocorrer com a retomada de uma concretagem durante a execução de uma estrutura ou no caso de recuperação de uma estrutura deteriorada.

A ligação entre o concreto de reforço, concreto novo, e o concreto da peça a ser reforçada, concreto velho, é vital para garantir o comportamento conjunto da peça original e do reforço, ou seja, para que a peça reforçada trabalhe como uma peça monolítica.

Em algumas situações observam-se as ocorrências de juntas de concretagens, mesmo em concretos com resistências da ordem de $100 \mathrm{MPa}$, que, em decorrência, formam caminhos para a penetração de agentes agressivos, que irão deteriorar a armadura em curto espaço de tempo, disgregando o concreto e levando a estrutura à sua completa destruição.

A técnica de dopagem pode ser uma solução revolucionária para a garantia dessa ligação, melhorando essa região, podendo ser aplicada em vários casos: desde no tratamento de diversos tipos de substratos para receber chapiscos destinados a argamassas, até na recuperação de estruturas e no tratamento de zonas de interface entre concreto novo versus concreto velho, foco deste trabalho.

De acordo com Fagury (2002), é importante a aplicação de pastas de cimento Portland de alto desempenho, para contribuir com a aderência química entre o concreto novo e o velho, além de aderência física, como a escarificação do concreto.

Outro aspecto a ser avaliado é a escolha do material de reparo. O projetista deve conhecer as propriedades de diferentes tipos de materiais, locais onde foram usados com sucesso, experiência de outros profissionais com esses materiais, entre outras informações.

Usado em edifícios de grande altura, plataformas submarinas, pontes, viadutos, pavimentos de rodovias e pisos industriais, o concreto de alto desempenho se mostra promissor também nos reparos estruturais, já que a combinação de adições minerais e químicas, aliada à técnica de refinamento de poros, resulta na elevação das 
propriedades mecânicas e na durabilidade desse concreto.

O uso da sílica ativa, por exemplo, refina a microestrutura do concreto, criando uma estrutura porosa muito mais densa. Desse modo, essa adição contribui não apenas para tornar o concreto mecanicamente mais resistente mas também para torná-lo quimicamente mais resistente à agressividade do meio ambiente (MELO, 2000).

Cita-se, além disso, a pesquisa desenvolvida por Liborio (2002), em que ficou evidenciada a eficiência de sílicas ativas no consumo de hidróxido de cálcio, já nas primeiras idades, demonstrando o efeito pozolânico na melhoria da zona de interface entre pasta e agregado.

Neste trabalho é proposto um avanço no comportamento de um sistema de reparos, superficiais e estruturais, para estruturas de concreto que apresentam problemáticas patológicas e/ou em casos de ampliações, retomadas de concretagem mediante o emprego de concreto de alto desempenho.

\section{Programa experimental}

O estudo realizado por Liborio e Fagury (2002) evidenciou a necessidade de escarificação e aplicação de uma pasta de alto desempenho antes de o concreto novo ser lançado. Isso se deveu, naquela oportunidade, às restrições relacionadas ao desenvolvimento tecnológico e à ausência de materiais de geração aprimorada, como ocorreu com os superplastificantes e com o aprendizado da técnica de empacotamento de materiais, então restrita à indústria da cerâmica.

O desenvolvimento do programa experimental deste trabalho, apresentado a seguir, baseou-se no estudo desses autores. As vigas que serviram para análise do substrato, moldadas antes da execução do reparo, foram representadas por corpos de prova prismáticos com dimensões $0,15 \mathrm{~m}$ x $0,15 \mathrm{~m}$ x $0,50 \mathrm{~m}$. Para esse substrato produziu-se um concreto denominado neste trabalho de S (Tabela 1), que normalmente é utilizado na construção civil, com traço $1: 6,5$ e consistência $K=14 \mathrm{~cm}$ (tronco de cone)
Os materiais empregados foram cimento Portland composto com escória de alto-forno (CP II E 32), com massa específica de $2,96 \mathrm{~g} / \mathrm{cm}^{3}$, areia natural quartzosa (Areia A) e dois tipos de brita basáltica, brita $\mathrm{A}\left(\mathrm{D}_{\text {máx }}=12,5 \mathrm{~mm}\right)$ e brita $\mathrm{B}\left(\mathrm{D}_{\text {máx }}=19,0\right.$ $\mathrm{mm})$, cujas características encontram-se na Tabela 2. Com base no método da massa unitária no estado compactado seco, prescrito pela NBR NM 45:2006, foi feita a composição dessas duas britas, a fim de obter a máxima densidade, resultando em $40 \%$ de brita A e $60 \%$ de brita B.

Após a mistura dos materiais, as vigas foram moldadas em fôrmas de aço e adensadas com vibrador de agulha. Também foram moldados, para cada idade analisada, corpos de prova cilíndricos com $100 \mathrm{~mm}$ de diâmetro e $200 \mathrm{~mm}$ de altura (NBR 5738, ABNT, 2008), sendo três para determinação da resistência à compressão do concreto (NBR 5739, ABNT, 2007), três para a resistência à tração por compressão diametral (NBR 7222, ABNT, 1994) e dois para o módulo estático de elasticidade à compressão (NBR 8522 , ABNT, 2008). Decorridas $24 \mathrm{~h}$ da moldagem, os corpos de prova foram acondicionados em câmara úmida até a data de ensaio. Os corpos de prova prismáticos foram ensaiados aos 28 e 56 dias de idade à tração na flexão (NBR 12142, ABNT, 1991), sendo solicitados até a ruína na condição de flexão pura.

Dando início ao tratamento da zona de interface, ou seja, iniciando-se o procedimento de reparo das vigas, foi realizada, logo após o ensaio de tração na flexão, a escarificação manual das duas superfícies geradas, executada radialmente, das arestas para o centro, com o objetivo de melhorar a aderência física entre essas partes.

Após a escarificação e a retirada de partes soltas das duas superfícies, os corpos de prova prismáticos foram imersos em água, durante o período de $24 \mathrm{~h}$, para que a superfície escarificada apresentasse um estado de saturação tal que, no instante da aplicação do concreto novo, se dispusesse de água para cura da junta e se evitasse a perda de água desse concreto para o do substrato. Com o término do período de imersão, os mesmos foram retirados da água e aguardou-se $1 \mathrm{~h}$ para a secagem superficial, condição saturada, com superfície seca. 


\begin{tabular}{|c|c|c|c|c|}
\hline \multicolumn{2}{|c|}{ TRAÇO EM MASSA } & $1: 6,5$ & $1: 3,2$ & $1: 3,2$ \\
\hline \multicolumn{2}{|c|}{ Denominação neste trabalho } & Substrato $(\mathbf{S})$ & CAD & CAD com fibra \\
\hline \multicolumn{2}{|c|}{ Teor de argamassa $(\%)$} & 55,00 & 70,00 & 70,00 \\
\hline \multicolumn{2}{|c|}{ Relação água/aglomerante } & 0,63 & 0,35 & 0,35 \\
\hline \multicolumn{2}{|c|}{ Consumo de cimento $\left(\mathrm{kg} / \mathrm{m}^{3}\right)$} & 289,70 & 456,70 & 452,60 \\
\hline \multicolumn{2}{|c|}{ Consumo de sílica ativa $\left(\mathrm{kg} / \mathrm{m}^{3}\right)$} & - & 58,10 & 57,60 \\
\hline \multicolumn{2}{|c|}{ Consumo de areia $\left(\mathrm{kg} / \mathrm{m}^{3}\right)$} & 905,30 & $1.042,30$ & $1.033,00$ \\
\hline \multicolumn{2}{|c|}{ Consumo de brita $\left(\mathrm{kg} / \mathrm{m}^{3}\right)$} & 977,80 & - & - \\
\hline \multicolumn{2}{|c|}{ Consumo de pedrisco $\left(\mathrm{kg} / \mathrm{m}^{3}\right)$} & - & 676,90 & 670,90 \\
\hline \multicolumn{2}{|c|}{ Consumo de aditivo $\left(\mathrm{kg} / \mathrm{m}^{3}\right)$} & - & 7,70 & 7,70 \\
\hline \multicolumn{2}{|c|}{ Consumo de fibra $\left(\mathrm{kg} / \mathrm{m}^{3}\right)$} & - & - & 0,50 \\
\hline \multicolumn{2}{|c|}{$\begin{array}{c}\text { Massa específica }\left(\mathrm{kg} / \mathrm{m}^{3}\right) \\
\text { NBR NM } 47 \text { (ABNT, 2002) }\end{array}$} & 2355,00 & 2422,00 & 2401,00 \\
\hline \multirow{3}{*}{$\begin{array}{c}\text { Resistência } \\
\text { média à } \\
\text { compressão } \\
\text { (MPa) }\end{array}$} & 03 dias & 18,50 & 55,30 & 54,90 \\
\hline & 07 dias & 23,90 & 74,80 & 74,30 \\
\hline & 28 dias & 29,00 & 102,60 & 98,50 \\
\hline \multirow{2}{*}{$\begin{array}{l}\text { Módulo de } \\
\text { elasticidade } \\
\text { (GPa) }\end{array}$} & 07 dias & 26,70 & 37,80 & 37,40 \\
\hline & 28 dias & 34,90 & 42,10 & 42,00 \\
\hline
\end{tabular}

Nota: os consumos dos materiais foram calculados considerando a massa específica (consumo prático) Tabela 1 - Características dos traços elaborados

\begin{tabular}{|c|c|c|c|c|}
\hline Agregado & $\begin{array}{c}D_{\text {máx }}(\mathbf{m m}) \\
\text { NBR } 7211(A B N T, \\
2005)\end{array}$ & \multicolumn{2}{|c|}{$\begin{array}{l}\text { Massa específica } \\
\qquad\left(\mathrm{g} / \mathrm{cm}^{3}\right)\end{array}$} & $\begin{array}{c}\text { Massa unitária }\left(\mathrm{g} / \mathrm{cm}^{3}\right) \\
\text { NBR NM } 45 \text { (ABNT, 2006) }\end{array}$ \\
\hline Areia A & 2,4 & \multirow{3}{*}{$\begin{array}{l}\text { NBR NM } 52 \\
(\text { ABNT, 2003) }\end{array}$} & \multirow{3}{*}{2,63} & 1,58 \\
\hline Areia B & 1,2 & & & 1,38 \\
\hline Areia C & $2,5 \times 10^{-2}$ & & & - \\
\hline Brita A & 12,5 & \multirow{3}{*}{$\begin{array}{l}\text { NBR NM } 53 \\
(\text { ABNT, 2003) }\end{array}$} & \multirow{3}{*}{2,86} & 1,49 \\
\hline Brita B & 19,0 & & & 1,49 \\
\hline Pedrisco & 9,5 & & & 1,46 \\
\hline
\end{tabular}

Tabela 2 - Características dos agregados empregados

\begin{tabular}{|c|c|}
\hline \multicolumn{2}{|c|}{ Traço da pasta de cimento: $1: x=0,37: S P=1,5 \%: S A=10 \%$} \\
\hline Materiais & Descrição \\
\hline Cimento Portland & CPV ARI RS - Grupo Holcim S.A. \\
\hline Aditivo superplastificante $(1,5 \%)$ & Sikamente® 300 - SIKA S.A. \\
\hline Adição $(10 \%)$ & ELKEM Microsilica ${ }^{\circledR}$ \\
\hline Relação água/cimento & $0,37 \mathrm{~kg} / \mathrm{kg}$ \\
\hline
\end{tabular}

Nota: a adição da sílica ativa (10\%) é calculada em substituição à massa absoluta de cimento do traço; já do aditivo superplastificante $(1,5 \%)$, é em função do total de aglomerantes, em massa.

Fonte: adaptado de Fagury (2002)

Tabela 3 - Dosagem da pasta de alto desempenho

Dando sequência ao tratamento da zona de interface, iniciou-se a aplicação da técnica de dopagem com os tratamentos químicos das duas superfícies. Neste trabalho foram avaliados três procedimentos, a saber:

(a) RL: aplicação da pasta de alto desempenho, composta de cimento CP V ARI RS, sílica ativa e aditivo superplastificante Sikamente ${ }^{\circledR}$ 300, com massa específica de $1,22 \mathrm{~g} / \mathrm{cm}^{3}$, e posterior lançamento do concreto de alto desempenho (CAD), não excedendo 5 min entre as operações. A dosagem dessa pasta encontra-se na Tabela 3; (b) RP: impregnação por via seca do pó composto de cimento CP V ARI RS e sílica ativa (Fe-Si) e posterior lançamento do $\mathrm{CAD}$, não excedendo 5 mim entre as operações; e

(c) R e RF: lançamento direto do CAD e CAD com adição de fibras de polipropileno respectivamente.

No procedimento RL há o lançamento do $\mathrm{CAD}$, diferenciando-se do procedimento avaliado por Fagury (2002), o qual lançou concretos convencionais. Para efeito comparativo, fez-se o 
procedimento RP usando a mesma composição do RL.

Buscando aprimorar o tratamento químico usado por Fagury (2002), através da eliminação da etapa de aplicação da pasta, o CAD foi lançado diretamente no concreto velho, conforme procedimentos R e RF. Para eliminar a aplicação da pasta, que tem por função promover a ligação entre os concretos novo e velho, e lançar diretamente o CAD, foi preciso agregar características de adesão e fluidez durante seu processo de dosagem.

Dessa forma, pode-se dizer que a técnica de dopagem apresenta-se de forma implícita nos procedimentos $\mathrm{R}$ e RF, uma vez que consiste na dosagem adequada de um concreto (CAD), valendo-se do uso de cimento de alta resistência, sílica ativa e aditivo superplastificante, aliado ao empacotamento de partículas e à baixa relação água/aglomerante. A Figura 1 mostra a aplicação do pó, da pasta de alto desempenho e o lançamento direto do CAD.

O CAD, utilizado no reparo dos corpos de prova prismáticos (Tabela 1), foi dosado para apresentar características como autoadensável, alta resistência e elevada adesão, sendo produzido com cimento CPV ARI RS, sílica ativa de ferro-silício, em substituição volumétrica de $15 \%$ ao cimento, com as respectivas massas específicas de 3,08 e 2,10 $\mathrm{g} / \mathrm{cm}^{3}$, e aditivo superplastificante ADVA Cast, com massa específica de $1,05 \mathrm{~g} / \mathrm{cm}^{3}$. Os agregados utilizados foram três tipos de areia natural quartzosa (areia A, areia B e areia C) e pedrisco basáltico $\left(\mathrm{D}_{\text {máx }}=9,5 \mathrm{~mm}\right)$, com características apresentadas na Tabela 2 .

Aplicando-se a técnica de empacotamento de partículas, a fim de obter a máxima densidade, foi feita a composição dessas três areias. Para isso, utilizou-se o método da massa unitária no estado compactado seco (NBR NM 45, ABNT, 2006), que resultou em $63 \%$ de areia $\mathrm{A}, 27 \%$ de areia $\mathrm{B}$ e $10 \%$ de areia $\mathrm{C}$.

Para o reparo dos prismas com adição de fibra foi utilizada a mesma composição do CAD, adicionando fibra sintética de polipropileno aditivado Fiberlock, para efeito comparativo. Essa fibra tem $10 \mathrm{~mm}$ de comprimento e $0,90 \mathrm{~g} / \mathrm{m}^{3} \mathrm{de}$ peso específico, devendo ser usada na quantidade de $0,5 \mathrm{~kg} / \mathrm{m}^{3}$ de concreto, conforme especificado pelo fabricante. As características dos traços empregados neste trabalho são mostradas na Tabela 1.

A caracterização do CAD foi feita para as idades de 1, 3, 7, 28, 56 e 91 dias, a partir dos ensaios de resistência à compressão (NBR 5739:2007), resistência à tração por compressão diametral (NBR 7222, ABNT, 1994), módulo de elasticidade ou módulo de deformação tangente inicial (NBR 8522, ABNT, 2008) e resistência à flexão (NBR 12763, ABNT, 1992).

Após realizados os procedimentos de reparo, os corpos de prova prismáticos recuperados ficaram com dimensões de $0,15 \mathrm{~m} \times 0,15 \mathrm{~m} \times 0,65 \mathrm{~m}$ e, transcorridas $24 \mathrm{~h}$, foram acondicionados em câmara úmida até a data de ensaio. Depois de 28 dias da execução do reparo, eles foram ensaiados à tração na flexão (NBR 12142:1991), na condição de flexão pura, sendo possível avaliar o desempenho da ligação entre o concreto novo e o velho.

\section{Apresentação e discussão dos resultados}

As Tabelas 1 e 2 apresentam, respectivamente, os traços elaborados e as características dos agregados. A Tabela 3 mostra a dosagem da pasta de alto desempenho.

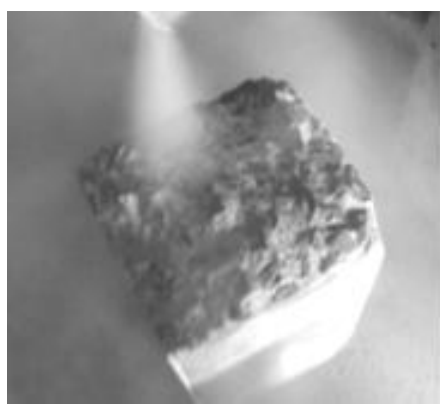

(a) Pó por via seca - RP

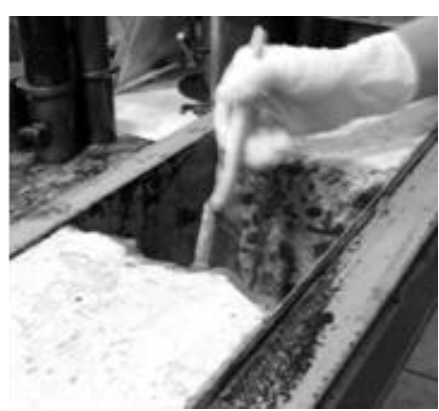

(b) Pasta de alto desempenho -RL

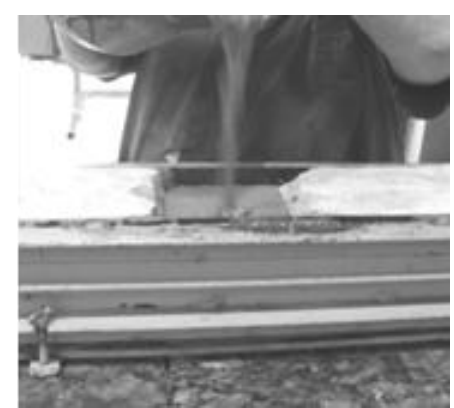

(c) $\mathrm{CAD}-\mathrm{R}$ e RF

Figura 1 - Procedimentos de reparo 
Conforme pode ser visto na Tabela 1 , o valor do consumo de cimento por metro cúbico de concreto para a produção do concreto de alto desempenho está em torno de $450 \mathrm{~kg}$, demonstrando que não há necessidade de um consumo de cimento maior que esse para obter alto desempenho quanto à resistência à compressão e ao módulo de elasticidade, o que normalmente acontece nas situações de reparo empregadas na construção civil.

Analisando os valores de massa específica dos traços elaborados (Tabela 1), observa-se que o CAD e o CAD com fibra são menos porosos que o concreto de substrato. Esse fato está associado ao emprego da técnica de empacotamento de partículas e ao uso de adições e aditivos.

A Tabela 4 apresenta os resultados de caracterização dos concretos de reparo $\mathrm{CAD}$, com e sem fibra de polipropileno, no estado fresco. A trabalhabilidade desses concretos foi avaliada segundo os ensaios de caixa-L e espalhamento, a fim de verificar a premissa de serem autoadensáveis.

Os limites aceitáveis sugeridos por Bartos e Grauers 1999 (apud GOMES, 2002) foram para concreto sem fibras. Quando se usa fibra, a tendência é modificar esses parâmetros, que dão maiores tempos, portanto os resultados da Tabela 4 são coerentes. Desse modo, pode-se dizer que esses concretos atenderam à premissa de ser autoadensável pelo fato de se mostrarem autonivelantes, ou seja, a relação entre as alturas final e inicial $\left(h_{2} / h_{1}\right)$ foi bem próxima ou igual a 1 , independentemente da presença ou não da fibra de polipropileno.

Além disso, ambas as misturas apresentaram elevada coesão e não foram observados sinais de segregação de seus materiais, podendo esse fato ser comprovado visualmente após os ensaios de tração por compressão diametral e flexão dos corpos de prova moldados com essas misturas (Figura 2).

Devem ser considerados também os efeitos da temperatura e umidade no preparo do concreto, que podem implicar pequenas alterações nos valores dos ensaios do concreto no estado fresco.
Para adequar os limites à necessidade de projeto, pode-se realizar correções na relação água/cimento de acordo com a temperatura e umidade.

As Figuras 3 e 4 mostram, respectivamente, os resultados dos ensaios de resistência à compressão axial simples e resistência à tração por compressão diametral do concreto de substrato (S) e dos concretos de reparo (CAD e CAD com fibra). Podese perceber que os valores de resistência do CAD, tanto à compressão axial simples quanto à tração por compressão diametral, praticamente não sofreram interferência significativa após a adição da fibra de polipropileno. Ao adicioná-la, houve uma pequena perda nos valores de compressão e um pequeno ganho nos de tração, ao longo da idade.

No entanto, avaliando a trabalhabilidade dos CAD com o auxílio da Tabela 4, pode-se notar que a quantidade de adição de fibra recomendada pelo fabricante, $0,5 \mathrm{~kg} / \mathrm{m}^{3}$, proporcionou uma queda em torno de $10 \%$ no resultado do ensaio de espalhamento, porém sem comprometer a premissa de ser autoadensável.

Ao analisar o consumo de cimento necessário para obter $1 \mathrm{MPa}$ de resistência à compressão axial simples, aos 28 dias de idade, tendo como base a Tabela 1 e a Figura 3, observa-se que no concreto de substrato foram necessários aproximadamente $10 \mathrm{~kg}$ de cimento CPII E32 para atingir essa resistência. Em contrapartida, foram necessários aproximadamente $4,5 \mathrm{~kg}$ de cimento CPV ARI RS para obter o mesmo $1 \mathrm{MPa}$ no concreto de alto desempenho.

Portanto, focando também a busca de um concreto sustentável na construção civil, o CAD produzido neste trabalho desmistifica a questão da exigência de alto consumo de cimento em obras de reparo, representando uma economia de cimento associada à excelente resistência mecânica.

A Figura 5 apresenta os resultados de resistência à flexão dos concretos de reparo. Esse ensaio foi realizado em amostras de concreto com dimensões de $(25 \times 65$ x 300) mm, observando que a adição da fibra de polipropileno praticamente não influenciou nos valores desse ensaio.

\begin{tabular}{c|c|c|c|c|c}
\hline \multirow{2}{*}{ Traço } & \multicolumn{3}{|c|}{ Caixa $\mathbf{L}$} & \multicolumn{2}{c}{ Espalhamento } \\
\cline { 2 - 6 } & $\left(\mathbf{h}_{\mathbf{2}} / \mathbf{h}_{\mathbf{1}}\right)^{\mathbf{1}}$ & $\mathbf{t}_{\mathbf{2 0}}(\mathbf{s})^{\mathbf{2}}$ & $\mathbf{t}_{\mathbf{4 0}}(\mathbf{s})^{\mathbf{3}}$ & $\mathbf{d}(\mathbf{c m})$ & $\mathbf{t}_{\mathbf{5 0}}(\mathbf{s})^{\mathbf{4}}$ \\
\hline Reparo (R) & 1,00 & 1,0 & 3,0 & 80,0 & 3,0 \\
\hline Reparo com fibra (RF) & 0,98 & 2,0 & 6,0 & 70,0 & 5,0 \\
\hline Limite aceitável $^{*}$ & $\geq 0,8$ & $0,5 \leq \mathrm{t}_{20} \leq 1,5$ & $2,0 \leq \mathrm{t}_{40} \leq 3,0$ & 60 a 70 & $3,0 \leq \mathrm{t}_{50} \leq 7,0$ \\
\hline
\end{tabular}

* Segundo Bartos e Grauers 1999 apud Gomes (2002).

1 Relação entre as alturas final $\left(h_{2}\right)$ e inicial $\left(h_{1}\right)$

2 É o tempo em que o concreto alcança a marca de $20 \mathrm{~cm}$ na caixa- $\mathrm{L}$

3 É o tempo em que o concreto alcança a marca de $40 \mathrm{~cm}$ na caixa-L

${ }^{4}$ É o tempo que o concreto leva para atingir o diâmetro de $50 \mathrm{~cm}$ no slump flow

Tabela 4 - Resultados de caracterização dos CAD no estado fresco 


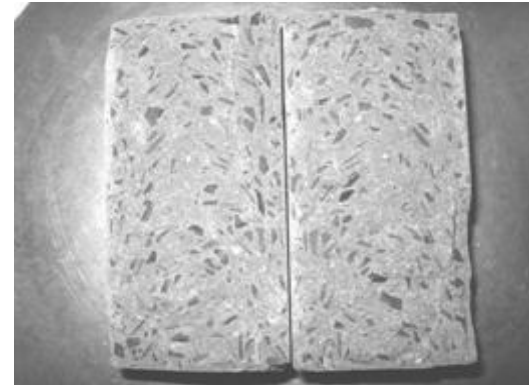

(a) Tração por compressão diametral

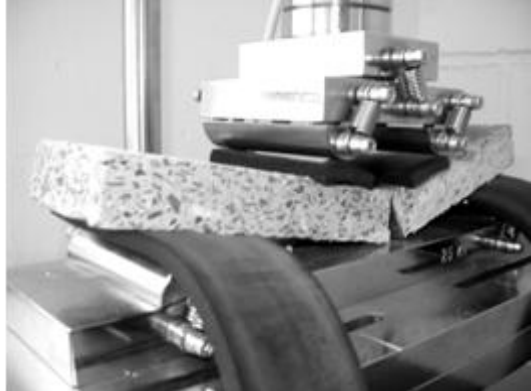

(b) Flexão

Figura 2 - Corpos de prova sem sinais de segregação de seus materiais

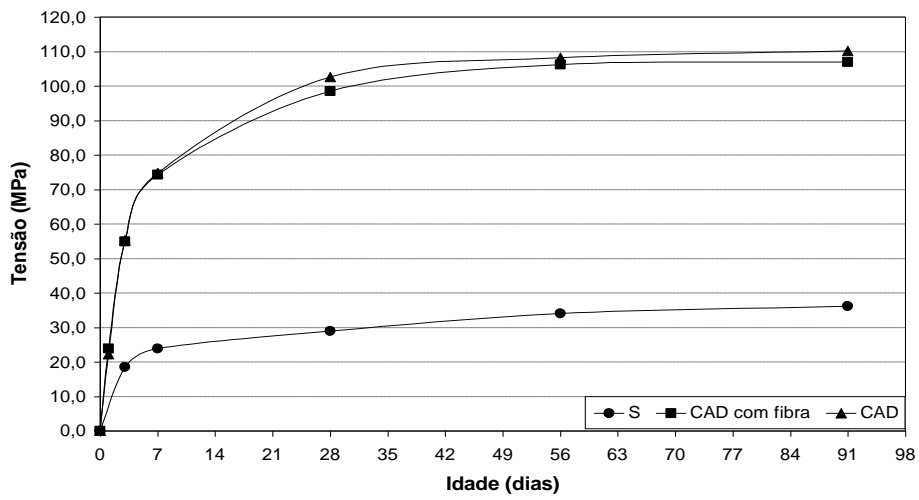

Figura 3 - Resistência à compressão axial simples dos concretos elaborados

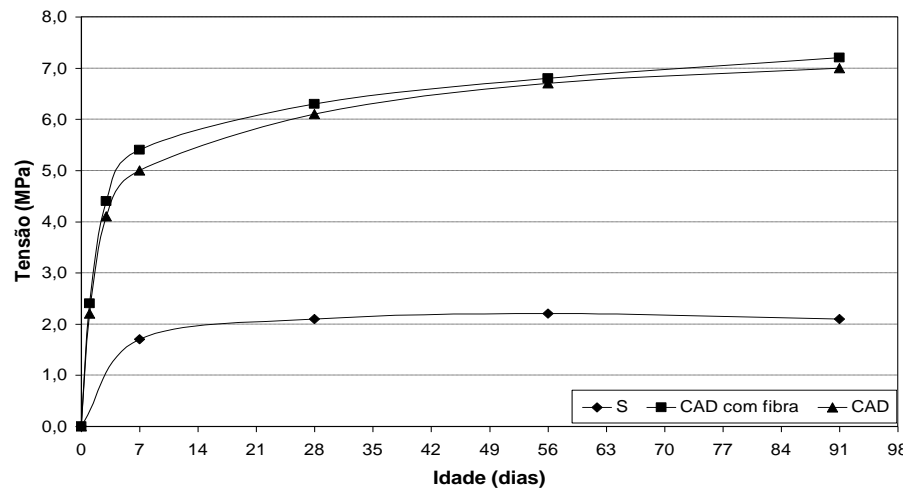

Figura 4 - Resistência à tração por compressão diametral dos concretos elaborados

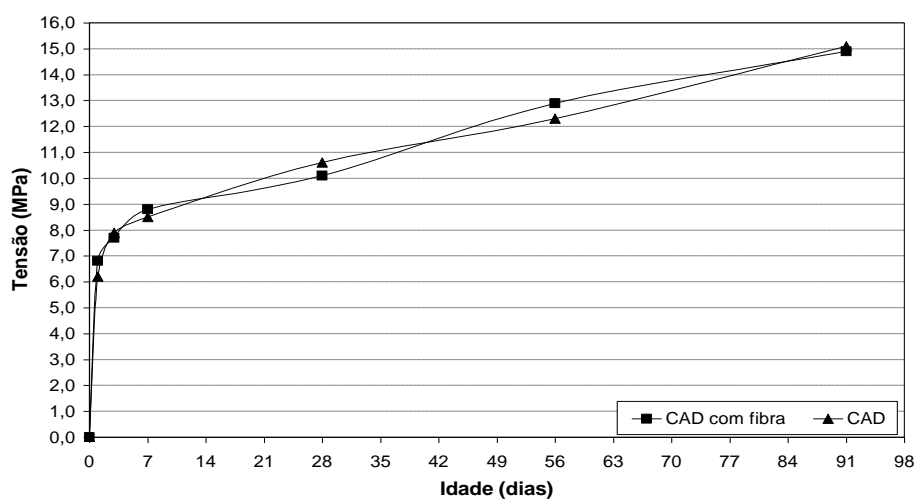

Figura 5 - Resistência à flexão dos CAD com e sem adição de fibra de polipropileno 
A Figura 6 apresenta a comparação do ensaio de tração na flexão realizado nas vigas sem e com o reparo. Em ambos os casos, a linha de ruptura apareceu no terço médio do vão, fato característico do ensaio de flexão na condição pura.

A eficácia da técnica de dopagem no tratamento da zona de interface entre esses concretos fica demonstrada quando a ruptura da viga ocorre na região do concreto de substrato (Figura 6) e/ou o concreto readquire sua tensão de flexão.

Na Figura 7 são mostrados os resultados de resistência à tração na flexão dos corpos de prova prismáticos antes do reparo, representados pelas colunas de ruptura aos 28 dias. As colunas de ruptura aos 56 dias representam os valores de resistência desse ensaio decorridos 28 dias do reparo. Apresentam-se também as médias de três vigas para cada procedimento de ligação (RL, RP, RF e R) e, para efeito comparativo, é apresentada a resistência à flexão, aos 28 e 56 dias de idade, da viga (S) com concreto de substrato.

Conforme concluído por Fagury (2002), é marcante a necessidade de um tratamento antes da aplicação de um concreto em contato com outro, de diferentes idades, no sentido de recuperar uma estrutura. Com base nisso, o procedimento com aplicação da pasta de alto desempenho (RL) mostrou-se eficiente no tratamento da zona de interface, uma vez que a ruptura da viga ocorreu na região do concreto de substrato e o concreto praticamente readquiriu sua tensão de flexão.

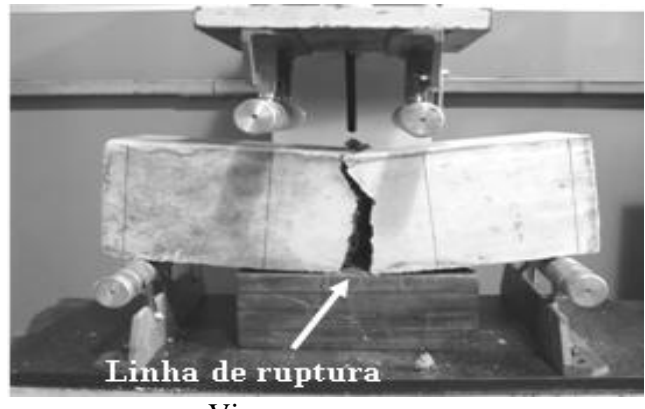

Viga sem o reparo
No procedimento RP, em que foi aplicado o pó composto de cimento e sílica ativa por via seca, ficou evidente que a ruptura da viga reparada com CAD ocorreu na ligação entre os concretos novo e velho, além do fato de esta viga ter recuperado somente $40 \%$ de sua resistência à tração na flexão. Esse procedimento de dopagem não foi eficiente no tratamento da zona de interface devido à camada espessa de pó aplicada, que causou uma barreira física, não deixando o $\mathrm{CAD}$ reagir com toda a camada de pó, nem atingir o substrato. Sabe-se que uma maior eficiência desse processo consiste em impregnar a região com uma solução de sílica em suspensão, seguida da concretagem. No entanto, como essa situação merece um controle mais elaborado (FUTIDA; LIBORIO, 2005), deixa-se para uma outra oportunidade, através de um estudo mais amplo, a apresentação desses resultados.

Fagury (2002) concluiu ainda que a simples aplicação de um concreto em contato com outro não é um procedimento adequado, mas na maioria das vezes é praticado. Buscando viabilizar o processo de reparo, foi estudado também neste trabalho o procedimento de ligação R (Figura 7), ou seja, o lançamento direto do CAD. A adequada dosagem desse concreto comprovou a viabilidade da aplicação direta dele, utilizando em sua composição materiais disponíveis comercialmente.

Figura 6 - Ensaio de tração na flexão
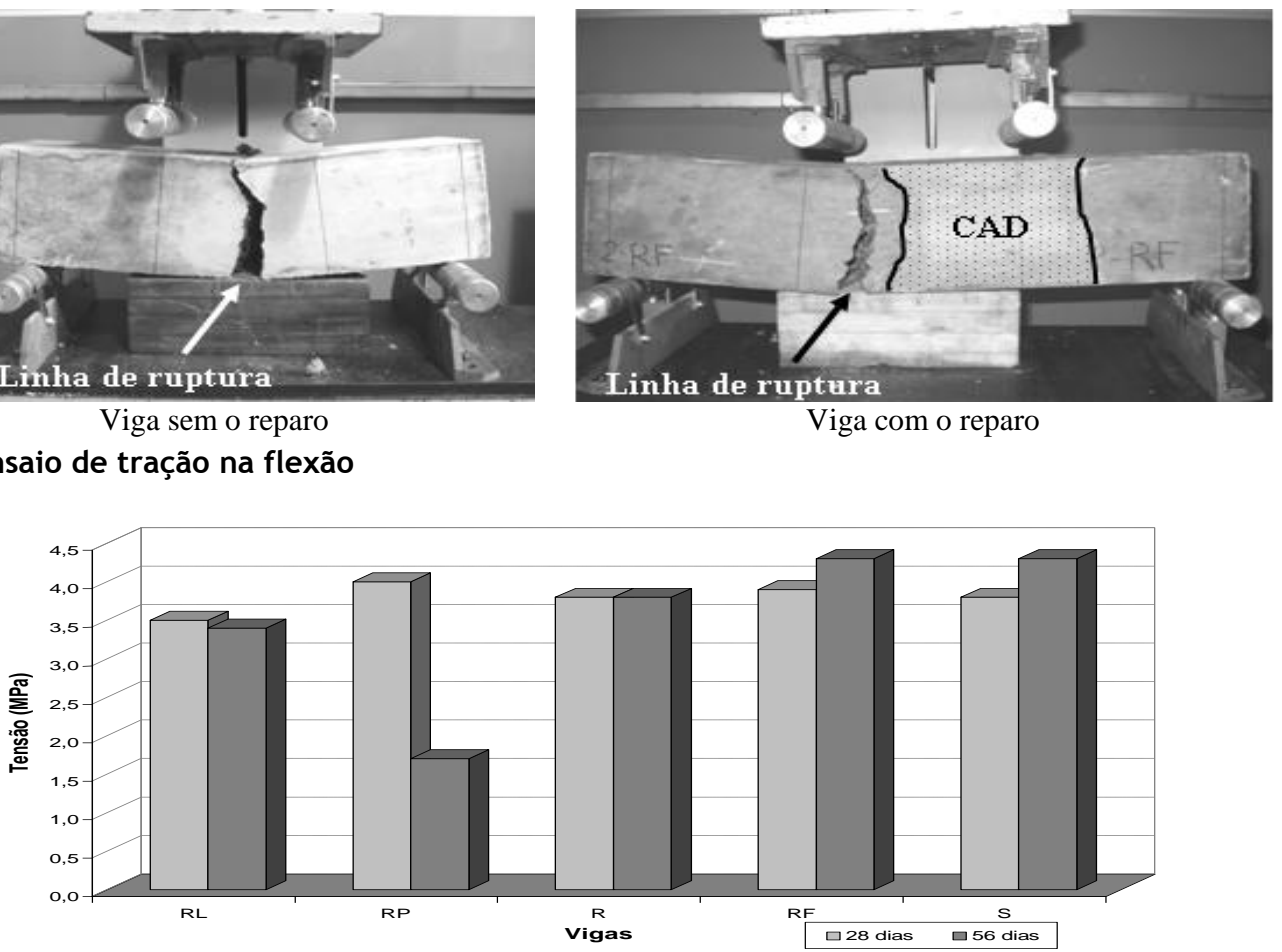

Figura 7 - Resistência à tração na flexão das vigas

174 Trigo, A. P. M.; Conceição, R. V. da; Liborio, J. B. L. 
Outro procedimento de dopagem avaliado foi o lançamento direto do CAD com fibra (RF). Podese perceber que o material de reparo, no caso o CAD com fibra, readquiriu totalmente sua tensão de flexão. Esse fato é comprovado ao se comparar a tensão de flexão do RF com a do substrato (S), ambos na coluna dos 56 dias (Figura 7).

Com exceção do procedimento com impregnação do pó (RP), percebe-se que a técnica de dopagem estudada neste trabalho, e representada pelos demais procedimentos (RL, R e RF), foi eficiente no tratamento da zona de interface.

A impregnação com pós deve ser feita com critério, a fim de não ultrapassar uma quantidadelimite correspondente àquela que se utiliza nos concretos de alto desempenho para eficiência da ligação.

Em seu estudo, Fagury (2002) comprovou que um reparo eficaz só seria possível caso fosse aplicada a pasta de alto desempenho, já que tanto o concreto novo quanto o velho eram convencionais. Nesse caso, fica evidente que o lançamento direto do concreto, sem agregar a tecnologia do alto desempenho na técnica de dopagem, não funcionaria.

Dessa forma, este trabalho contribui para o avanço no comportamento de um sistema de reparos para estruturas de concreto, mostrando que apenas o emprego de um concreto com propriedades de alto desempenho e dosado de forma a contemplar a técnica de dopagem é suficiente e resulta em maior eficiência do sistema.

Neste trabalho, considera-se dispensável a comparação dos resultados aqui mostrados com os obtidos empregando-se outras técnicas e materiais, em que poderiam ser abordados aspectos como ganho de resistência, facilidade de execução e custos envolvidos, uma vez que não se pretende estabelecer aqui uma técnica resolutiva, mas sim uma técnica alternativa a outros processos eficientes igualmente, como as ligações com epóxi, grautes, etc.

\section{Conclusões}

Um estudo de dosagem, levando em conta as propriedades de cada material envolvido, e um planejamento adequado de concretagem são, sem dúvida, fatores preponderantes e necessários para garantir qualidade e vida útil de uma estrutura de concreto.

A combinação de cimento de alta resistência, adição de sílica ativa e superplastificante é particularmente interessante para situações de reparo de estruturas de concreto. Com relação à resistência mecânica, já se esperava um desempenho notável por parte do CAD, com ou sem fibras de polipropileno, o que garante, em situações de reparo, um desempenho satisfatório na distribuição de esforços.

A adição de sílica ativa proporcionou elevada aderência ao substrato, devido ao fortalecimento da zona de interface, e o uso do aditivo superplastificante resultou em boa trabalhabilidade, não necessitando de vibrações em seu adensamento.

Portanto, valendo-se da técnica de dopagem e de conceitos de alto desempenho, conclui-se que a simples aplicação de um concreto em contato com outro, de diferentes idades, no sentido de recuperar uma estrutura, é um procedimento adequado que torna mais prático e, provavelmente, menos oneroso esse processo.

Destaca-se ainda a facilidade de disponibilização de materiais, com as adições não necessitando de estocagem especial, e em quanto se conseguiria economizar em comparação com a problemática que vai ocorrer caso não seja implementada a técnica. A empresa que realiza um empreendimento já poderá ter empacotado e dosado em seu almoxarifado uma mistura prévia de cimento Portland adequado e sílica ativa, por exemplo, acondicionados em embalagens plásticas, com vida útil maior que 6 meses.

Assim sendo, o sistema de reparo consequente do lançamento direto do CAD, com ou sem fibra de polipropileno, aqui estudado apresenta-se como uma real alternativa para situações de reparos e recuperações de elementos estruturais de concreto.

\section{Referências}

ASSOCIAÇÃO BRASILEIRA DE NORMAS TÉCNICAS (ABNT). NBR 5738: concreto: procedimento para moldagem e cura de corpos-deprova. Rio de Janeiro, 2008.

\section{ASSOCIAÇÃO BRASILEIRA DE NORMAS TÉCNICAS. NBR 5739: concreto: ensaio de compressão de corpos-de-prova cilíndricos concreto. Rio de Janeiro, 2007.}

ASSOCIAÇÃO BRASILEIRA DE NORMAS TÉCNICAS. NBR 7211: agregado para concreto: especificação. Rio de Janeiro, 2005.

\section{ASSOCIAÇÃO BRASILEIRA DE NORMAS TÉCNICAS. NBR 7222: argamassa e concreto: determinação da resistência à tração por compressão diametral de corpos-de-prova cilíndricos. Rio de Janeiro, 1994.}


ASSOCIAÇÃO BRASILEIRA DE NORMAS TÉCNICAS. NBR 8522: concreto: determinação do módulo estático de elasticidade à compressão. Rio de Janeiro, 2008.

\section{ASSOCIAÇÃO BRASILEIRA DE NORMAS} TÉCNICAS. NBR 12142: concreto: determinação da resistência à tração na flexão em corpos-deprova prismáticos. Rio de Janeiro, 1991.

\section{ASSOCIAÇÃO BRASILEIRA DE NORMAS}

TÉCNICAS. NBR 12763: rochas para revestimento: determinação da resistência à flexão. Rio de Janeiro, 1992.

\section{ASSOCIAÇÃO BRASILEIRA DE NORMAS} TÉCNICAS. NBR 45: agregados: determinação da massa unitária e do volume de vazios. Rio de Janeiro, 2006.

\section{ASSOCIAÇÃO BRASILEIRA DE NORMAS}

TÉCNICAS. NBR 47: concreto: determinação do teor de ar em concreto fresco - método pressométrico. Rio de Janeiro, 2002.

\section{ASSOCIAÇÃO BRASILEIRA DE NORMAS} TÉCNICAS. NBR 52: agregado miúdo: determinação de massa específica e massa específica aparente. Rio de Janeiro, 2003.

\section{ASSOCIAÇÃO BRASILEIRA DE NORMAS \\ TÉCNICAS. NBR 53: agregado graúdo: determinação de massa específica, massa específica aparente e absorção de água. Rio de Janeiro, 2003.}

BARTOS, P. J. M.; GRAUERS, M. SelfCompacting Concrete. Concrete, v. 33, n. 4, p. 913, 1999).

FAGURY, S. C. Concretos e Pastas de Elevado Desempenho: contribuição aos estudos de reparos estruturais e ligações entre concretos novo e velho, com tratamento da zona de interface. 2002. Dissertação (Mestrado em Ciência e Engenharia de Materiais) - Escola de Engenharia de São Carlos, Universidade de São Paulo, São Carlos, 2002.

FUTIDA, C. J.; LIBORIO, J. B. L. A Utilização de Agregado Graúdo Laterítico em Concretos de Elevado Desempenho. In: CONGRESSO INTERNACIONAL DE INICIAÇÃO CIENTÍFICA, 13., 2005, São Carlos. Anais... São Carlos: SIICUSP, 2005. 1 CD-ROM.
GOMES, P. C. C. Optimization and Characterization of High-Strength SelfCompacting Concrete. 2002. Tese (Doutorado em Engenharia Civil) - Escola Tècnica Superior d'Enginyers de Camins, Universitat Politècnica de Catalunya, Barcelona, 2002.

LARANJEIRAS, A. C. R., Estruturas de Concreto Duráveis: uma chave para o sucesso do desenvolvimento sustentável. In: SIMPÓSIO COMEMORATIVO INSTITUTO BRASILEIRO DO CONCRETO 30 ANOS, 2002, São Paulo. Anais... São Paulo: IBRACON, 2002. 1 CD-ROM

LIBORIO, J. B. L. Avanços Tecnológicos dos Concretos Estruturais nos Últimos 30 Anos. In: IBRACON. 30 Anos. São Paulo: 2002. 1 CDROM.

LIBORIO, J. B. L.; FAGURY, S. C. Concretos e Pastas de Elevado Desempenho: contribuição aos estudos dos reparos estruturais entre ligações entre concretos novo e velho, com tratamento da zona de interface. In: CONGRESSO BRASILEIRO DO CONCRETO: IBRACON, 44., Belo Horizonte, 2002. Anais... Belo Horizonte: IBRACON, 2002. 1 CD-ROM.

MELO, A. B. Influência da Cura Térmica (Vapor) sob Pressão Atmosférica no Desenvolvimento da Microestrutura dos Concretos de Cimento Portland. 2000. Tese (Doutorado em Interunidades em Ciência e Engenharia dos Materiais) - Escola de Engenharia de São Carlos, Universidade de São Paulo, São Carlos, 2000.

SILVA, V. M. Contribuição ao Estudo da Carbonatação em Concretos e Argamassas Executados Com e Sem Adição de Sílica Ativa. 2002. Dissertação (Mestrado em Ciência e Engenharia de Materiais) - de Engenharia de São Carlos, Universidade de São Paulo, São Carlos, 2002.

SILVA, F. G. Estudo de Concretos de Alto Desempenho Frente à Ação de Cloretos. 2006. Tese (Doutorado em Interunidades em Ciência e Engenharia de Materiais) - Escola de Engenharia de São Carlos, Universidade de São Paulo, São Carlos, 2006.

\section{Agradecimentos}

Agradecemos a Grupo Holcim S.A., ELKEM Microsilica ${ }^{\circledR}$, GRACE Brasil Ltda. e SIKA S.A., pela doação de materiais. 